\section{La forma en que el grado de inseguridad y la violencia actual truncaron la vida de un gran médico peruano}

\author{
The way the current level of \\ insecurity and violence cut short \\ the life of a great peruvian doctor
}

Señor editor:

La Asamblea número 49 de la Organización Mundial de la Salud (OMS), en el año 1996, declaró la violencia como un problema de salud pública, debido al dramático incremento a nivel mundial de las lesiones intencionales que afectaban a las personas, al encontrarse serias consecuencias inmediatas y a largo plazo en dichos individuos, familias, comunidades y países. Se reconoció que los trabajadores en salud son los primeros en evidenciar este problema social por su capacidad técnica única y su posición en la comunidad para ayudar a las personas en riesgo. ${ }^{1}$

El homicidio intencional se define como la muerte de forma ilegal resueltamente infligida a una persona por otra; es reconocido como el principal y más confiable indicador de las muertes violentas en todo el mundo y, en ciertas circunstancias, un representante confiable del crimen violento e indicador de los niveles de seguridad ciudadana dentro de los países. ${ }^{2}$ En 2012, la OMS estimó una tasa total mundial de 6,7 homicidios por 100000 habitantes, que disminuyó en comparación con el periodo 2000-2012 donde llegó a ser de ocho homicidios. Sin embargo, la reducción mayor se dio en los países con alto ingreso económico., ${ }^{3,4}$

En el Perú hay una discrepancia en las tasas de homicidios, según las fuentes consultadas. De acuerdo con la OMS, en el 2012 la tasa fue de 11 homicidios por 100000 habitantes..$^{5}$ El mismo organismo, teniendo como fuente al Ministerio del Interior del Perú, informa tasas de 4 y 9,6 para los años 2002 y 2011, respectivamente. ${ }^{4}$ La United Nations Office on Drugs and Crime (UNODC) señala tasas de 5 y 9,6 durante los años 2000 y 2012, respectivamente. ${ }^{2}$ Por otro lado, el Comité Estadístico Interinstitucional de la Criminalidad (CEIC) del Perú informa tasas de 5,43; 6,53 y 6,61 para los años 2011, 2012, y 2013, respectivamente. ${ }^{6}$ Ante estos datos, podemos inferir que la violencia e inseguridad en nuestro país se ha incrementado con respecto al inicio del siglo XXI, presentando una tendencia creciente, a diferencia de la tasa perteneciente al contexto mundial, que se ha reducido.

Los médicos peruanos no hemos sido ajenos a este incremento de la violencia e inseguridad. Recientemente, un colega anestesiólogo, el doctor Telésforo León Velasco, fue asesinado en medio de una balacera desatada por delincuentes que intentaban asaltar el bus en el que se desplazaba desde la provincia piurana de Paita hacia la ciudad de Piura. La desgracia lo alcanzó al retornar de laborar en su consultorio particular, donde, a diferencia de muchos, él seguía brindando sus servicios en zonas de menor desarrollo, obedeciendo a un lazo de cariño y compromiso que lo unía con los pacientes de esa provincia. ${ }^{7.8}$ Fuimos testigos de esa verdadera vocación de servicio, donde el paciente era el dogma central y no el afán de beneficio económico. Nunca toleró el maltrato hacia ningún paciente y priorizaba a los que por razones de tiempo no alcanzaban a ser intervenidos en el turno previo, ingresándolos al quirófano con premura en su turno. Era muy solidario ante todo caso complicado, pues acudía a apoyar en lo que fuera necesario, aun sin que se le haya solicitado. 
Como la irreparable pérdida de nuestro colega, existen muchos homicidios más que privan a nuestra sociedad de elementos valiosísimos e irreemplazables. Pareciera que olvidamos que nuestro fin es protegernos y preservar la vida, desde donde nos toque actuar. ¿Qué podemos hacer para disminuir este tipo de violencia? Existen dos aspectos muy importantes de enfoque: control de la violencia y prevención. Esta última se lleva a cabo al modificar factores predisponentes a respuestas violentas, ya sean actitudinales 0 conductuales relacionadas con las situaciones sociales, económicas, políticas y culturales.,10 Dado el contexto que vive el país en la actualidad, probablemente el gobierno y la sociedad peruana no están realizando acciones en la magnitud y escala requerida en ambos aspectos para el control de la violencia e inseguridad. ${ }^{4}$

Debemos decir: "Basta a este día a día con sangre absurdamente derramada". Los gobernantes deben ver con claridad el llano en el que la violencia crece más a diario y deben actuar. Pero la sociedad también debe ser partícipe. La violencia no pregunta si afecta a alguien que delinque 0 a una persona de buenos valores morales y reparte dolor a diestra y siniestra. Es tiempo pues, de actuar en las semillas, apostar por nuevas generaciones, originar el cambio, apostar por la familia unida, amorosa, honesta y trabajadora, como lo hizo nuestro gran amigo y colega y, no solo con la familia de sangre, si no también con la familia laboral. Apostemos por organizarnos y borrar los zarpazos de violencia que nos lastiman con muertes a diario y extendamos lazos fortalecidos y esperanzados en un futuro mejor. Que nunca más un Telésforo León Velasco ni ningún otro peruano más caiga víctima de la inseguridad ciudadana.

\section{REFERENCIAS BIBLIOGRÁFICAS}

I. Organización Mundial de la Salud (OMS). Prevención de la violencia: una prioridad de salud pública (resolución WHA49.25). Actas de la 49 Asamblea Mundial de la Salud; 25 may 1996 [Internet]. Ginebra, Suiza: OMS; 1996. Resolución WHA49.25 [citado 7 jun 2015]. Disponible en: http://www.who.int/violence injury_prevention/resources/publications/en/WHA4925_spa.pdf

2. United Nations Office on Drugs and Crime (UNODC). Global study on homicide 2013 [Internet].Viena,Austria:United Nations;
2014 [citado 7 jun 2015]. Disponible en: https://www.unodc. org/documents/data-and-analysis/statistics/GSH20I3/20I4_ GLOBAL HOMICIDE BOOK web.pdf

3. Global Health Observatory $(\overline{\mathrm{G}} \mathrm{HO})$ data: Violence prevention [Internet]. Ginebra, Suiza: World Health Organization. c2015 - [citado 7 jun 2015]. Disponible en: http://www.who.int/gho/ violence/en/

4. Organización Mundial de la Salud (OMS), Oficina de las Naciones Unidas contra la Droga y el Delito (UNODC). Informe sobre la situación mundial de la prevención de la violencia 2014 [Internet]. Ginebra, Suiza: OMS; 2014 [citado 7 jun 2015]. Disponible en: http://apps.who.int/iris/bitstream//0665//45089///WHO_ NMH_NVI_14.2_spa.pdf

5. Global Health Observatory data repository: homicide estimates by country [Internet]. Ginebra, Suiza:World Health Organization. c2015 - [citado 7 jun 2015]. Disponible en: http://apps.who.int/ gho/data/node.main.VIOLENCEHOMICIDE!lang=en

6. República del Perú, Comité Estadístico Interinstitucional de la Criminalidad, Ministerio de Justicia y Derechos Humanos. Homicidios en el Perú, contándolos uno a uno 2012. Lima, Perú: Studio Creativo Punto Com; 2014 [citado 7 jun 2015]. Disponible en: http://www.minjus.gob.pe/wp-content/uploads/2014/07/ HOMICIDIOS-PERU-20I2I.pdf

7. Indignación y rabia (carta) [Internet]. Piura, Perú Diario El Tiempo; 26 may 2015 [citado 7 jun 20I5]. Disponible en: http://webcache.googleusercontent. com/search? $q=$ cache: $q v 5 R-b b V i A c]$ : eltiem po. pe/\%3Fp\%3D76350+\&cd=2\&hl=es\&ct=clnk\&client=opera

8. Vega MR. Tefo... un hombre excepcional [Internet]. Piura, Perú: Semana, Diario El Tiempo; 7 jun 2015 [citado 7 jun 2015]. Disponible en: http://eltiempo.pe/wp-content/uploads/2015/06/ PDF-Semana-070615.pdf

9. Krug E, Dahlberg L, Mercy JA,ZwiAB, Lozano R, editores. Informe mundial sobre la violencia y la salud [Internet].Washington D. C., EU. UU.: Organización Panamericana de la Salud; 2003 [citado 7 jun 20I5]. Disponible en: http://iris.paho.org/xmlui/bitstream/ handle/I23456789/725/92753 I5884.pdf?sequence=I

10. Organización Panamericana de la Salud. Prevención de la violencia: la evidencia [Internet]. El Paso, Texas: OPS; 2013 [citado 7 jun 2015]. Disponible en: http://apps.who.int/iris/ bitstream/I0665/8567I/I/97892753 I7488_spa.pdf

\section{Carlos Javier Shiraishi-Zapata}

Médico anestesiólogo. Hospital III José Cayetano Heredia, EsSalud, Piura. Hospital II Talara, EsSalud, Talara.

Yovanky Miluska More-Vilela

Médico anestesiólogo. Hospital III José Cayetano Heredia, EsSalud, Piura. Hospital Santa Rosa, MINSA, Piura.

\section{Correspondencia}

Dr. Carlos Shiraishi Zapata

shiraishi52@hotmail.com

Fecha de recepción: 14 de junio de 2015

Fecha de aceptación: 30 de junio de 2015 